\title{
CARACTERÍSTICAS MICROCLIMÁTICAS DE PRIMAVERA-VERÃO, NO HORTO FLORESTAL (SÃO PAULO).
}

\author{
Maria Helena de A. Mello (1) \\ Manoel Carlos de Oliveira (I) \\ Luct H. Nunes (1) \\ Amauri D. Garcia (1)
}

\begin{abstract}
RESUMO - O Horto Florestal de São Paulo localiza-se ao norte da cidade de São Paulo, nos primeiros contrafortes da Serra da Cantareira e faz divisa com a reserva florestal situada nessa serra. $O$ embasamento geológico corresponde ao Pré-Cambriano, aí representado por granitos. Os solos são basicamente Podzólicos vermelho-amarelo, intergrade para o Latossolo vermelho-amarelo. A área era coberta por floresta latifoliada tropical de planalto. No setor norte ainda existe uma ampla mancha florestal. Na área abrangida por esse Horto, foi desenvolvido um estudo procurando caracterizar o comportamento microclimático, no decorrer da primavera-verão, em funçāo de alguns aspectos da topografia e dos vários povoamentos vegetais. Notou-se que existe uma diversidade microclimática que se evidencia ora pela variação das condiçōes térmicas, ora pela variação da umidade.
\end{abstract}

\begin{abstract}
The Horto Florestal lies within the Cantareira Mountain Range in the north of São Paulo city, bordering a forest reserve. Geologically, precambrian rocks occurs in its area. The soil are mainly Podsols red-yellow intergrading to Latosols red-yellow. The highland tropical forest covered the area and still appears in the adjacent forest reserve. The purpose of the piesent research is to understand Horto Florestal microclimate, during the spring-summer, and its relation to topography and vegetation. A microclimate diversification related either to temperature or humidity was recognized.
\end{abstract}

Key-words: Cantareira Mountain Range, Microclimate conditions

\section{Introdução}

O Parque Estadual da Capital (Horto Florestal) está situado na zona norte da cidade

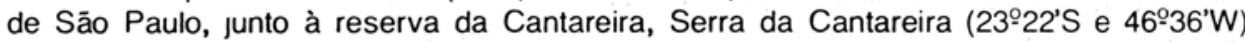
abrangendo uma área de 174 ha.

Essa área está localizada no Planalto Altântico, mais especificamente no Planalto Paulistano, ao norte da Bacia Sedimentar de São Paulo. O embasamento geológico do parque corresponde a rochas cristalinas do Pré-Cambriano, constituído em sua maior parte por granitos (EMPLASA 1980), sobre os quais se desenvolvem solos com textura argiloarenosa e compactos, com espessura média de 1 metro, variando conforme a posição topográfica. Ocorrem basicamente solos Podzólicos vermelho-amarelo intergrade para latossolos vermelho-amarelo (Brasil.Min.Agr. 1960).

$\mathrm{O}$ relevo se apresenta fortemente ondulado e montanhoso, com vertentes longas e abruptas, com declividades médias variando entre 5 e $40 \%$.

A vegetação residual predominante na área é a floresta sempre verde de planalto e caracteriza-se por ser latifoliada tropical, sub-úmida a úmida (Eiten 1970), aparecendo nas encostas da Serra da Cantareira. Ao lado da vegetação natural foram introduzidas várias espécies lenhosas arbóreas exóticas, desde o início do século. Esses povoamentos formam bosques homogêneos que são utilizados para pesquisa, com finalidade comercial, educativa e de lazer.

(1) Instituto Geológico - Av. Miguel Stéfano, 3900 - 04301 São Paulo - SP. 
O referido parque, em decorrência de sua localização (periferia da cidade de São Paulo) e dimensão (174 ha.) pode ser classificado, segundo a nomenclatura alemã (Schindler 1975), como parque distrital. Tal tipo de parque possui dimensões acima de 100 ha. e está situado a uma distância de $1500 \mathrm{~m}$ para se atingí-lo a pé. Por meio de transporte público ou particular gasta-se aproximadamente de 20 a 30 munitos. Isto significa que um parque dessa natureza é para ser usufruído por familias ou individualmente durante o dia, ou período do dia (manhã ou tarde). Neste sentido, deve possuir inúmeras funçōes e locais para passeios a pé, para lazer ativo e passivo, para estacionamentos. Deve possuir equipamentos para atender a uma clientela que permaneceria durante o tempo mencionado.

O planejamento de um parque dessas dimensões e finalidades necessita ser relativamente complexo para se propor uma organização espacial visando valorizar as inúmeras funçōes existentes em sua área. Para se chegar a esse tipo de planejamento torna-se necessário elaborar alguns estudos básicos sobre as características ambientais da área. A equipe autora deste trabalho se propos a realizar um estudo das características microclimáticas do Horto Florestal, no decorrer da época do ano, primavera-verão, em que o mesmo torna-se mais frequentado para fins de lazer. Para tanto, levou-se em conta certos aspectos da morfometria, da vegetação e de algumas das funções inerentes ao espaço territorial em questão. Os resultados obtidos até aqui şe constituem numa compartimentação microclimática e topográfica. Essa compartimentação viabiliza uma posterior análise das influências dessas variáveis ambientais na vegetação e nas diversas funções existentes no parque. Este trabalho iria subsidiar um amplo plano de manejo cuja finalidade seria racionalizar e implementar as diversas atividades exercidas na área do Horto.

\section{Material e Métodos}

\section{Determinação das características topográficas.}

Foram estudadas 3 características topográficas que são muito importantes para definir condiçōes potenciais da paisagem. São elas: orientação de vertente, hipsometria e declividade.

A escala original de mapeamento foi de 1:2000, pois esses estudos devem ser efetuados em escala grande a fim de se obter uma maior precisão quanto aos subsídios para planejamento.

Para a elaboração da carta de orientação de vertente foi utilizado um ábaco, desenvolvido de acordo com as coordenadas métricas do sistema UTM da carta em questão, levando-se em conta a direção das curvas de nivel em relação aos pontos cardeais (Oliveira 1984). Foram consideradas 8 classes de orientação de vertentes, representadas inicialmente em cores e transpostas para o mapa original em números para facilitar o trabalho de integrar as mesmas com os outros fatores topográficos. Obteve-se assim a seguinte classificaçāo: $N=1 ; N E=2 ; E=3 ; S E=4 ; S=5 ; S W=6 ; W=7 ; N W=8$.

A carta hipsométrica foi elaborada com intervalos de classes de $10 \mathrm{em} 10$ metros. Para se ter a sensação de volume foi usada uma tabela de cores, posteriormente tranformada em letras maiúsculas, guardando entre si a seguinte correspondência:

$$
\begin{aligned}
& 750-760=\mathrm{A} ; 760-770=\mathrm{B} ; 770-780=\mathrm{C} ; \\
& 780-790=\mathrm{D} ; 790-800=\mathrm{E} ; 800-810=\mathrm{F} ; \\
& 810-820=\mathrm{G} ; 820-830=\mathrm{H} ; 830-840=\mathrm{I} \\
& 840-850=\mathrm{J} ; 850-860=\mathrm{K} ; 860-870=\mathrm{L} ; \\
& 870-880=\mathrm{M} .
\end{aligned}
$$

A carta de declividade foi organizada através de curvas de nível de 5 em 5 metros e lançada em classes onde cada intervalo representa porcentagem (De Biasi 1973). Para a área em estudo achou-se representativo a divisão em 5 classes. 0 mapa básico foi reali- 
zado em cores e posteriormente estas foram transformadas em letras minúsculas. As classes da declividade são: $0-5 \%=a ; \quad 5-15 \%=b ; \quad 15-25 \%=c$; $25-40 \%=$ d; acima de $40 \%=$ e.

\section{Compartimentação topográfica.}

Através do método conhecido como sistema de avaliação paramétrica (Mitchell 1973) foram analisados os fatores; orientação de vertente, hipsometria e declividade, obtendo-se uma série de compartimentos topográficos, indicativos das condiçőes dos terrenos. (Fig. 1). Essas condiçōes expressam algum grau de restrição quanto ao uso do espaço, ao se pretender a implantação de equipamentos relacionados com as várias funçōes usualmente existentes numa área como a do Horto Florestal. Este nível de análise é caracterizado como uma abordagem preliminar de planejamento.

Foram identificados 3 compartimentos básicos: macro, mezo e micro compartimentos. Os macro-compartimentos representam as bacias hidrográficas que na área de estudo são três.

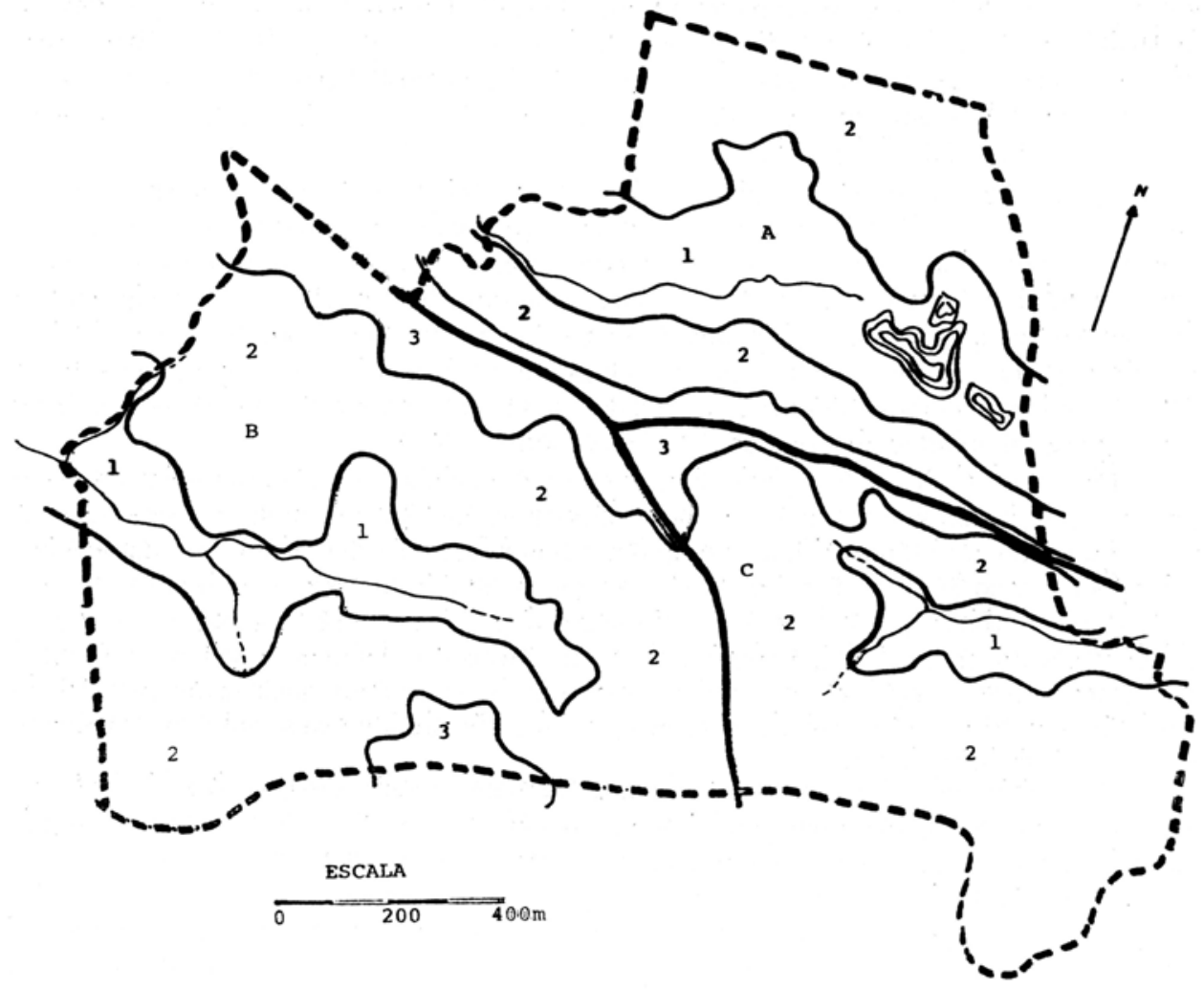

Fig. 1 - Compartimentos topográficos do Parque Estadual da Ciapital. macro-compartimento; meso-compartimento; 
Os mezo-compartimentos são segmentos topográficos onde há determinado arranjo de fatores topográficos. Foram representados com números: fundo de vale $=1$, vertente $=2$ e topo $=3$.

Os micro-compartimentos foram obtidos de acordo com o arranjo predominante dos fatores topográficos.

As classes de uso de acordo com os compartimentos receberam a seguinte classificação: classe I = uso sem restrição; classe II = uso com alguma restrição (área sujeita a inundação, solos hidromórficos); classe III = uso com restrição (área acidentada sujeita a influência climática Norte); classe IV = uso com grande restrição (área acidentada sujeita a influência climática Sul predominante).

Em relação às bacias hidrográficas encontra-se a seguinte situação (válida para as três bacias): classe 1 = compartimento 3 ; classe $\|$ = compartimento 1 ; classe $I I I=$ compartimento 2 (setor Norte); classe IV = compartimento 2 (setor Sul).

\section{Determinação das características climáticas.}

As análises dos elementos climáticos foram desenvolvidas tendo-se em vista 2 tipos de abordagem. $O$ primeiro, cujos resultados não serão discutidos no presente artigo, considera o Horto Florestal como uma área climaticamente homogênea, onde a caracterização climática pode ser inferida com base nas observaçōes efetuadas em 1 único ponto de observação, o ponto $\mathrm{P}_{\mathrm{o}}$ - estação meteorológica do Horto Florestal. Neste caso, as análises se limitaram aos niveis anual e mensal e se basearam numa série de 36 anos (1946-1981) de observações. Os dados desta série, fornecidos pelo INEMET (Inst. Nac. de Meteorologia), foram estatísticamente analisados com o principal objetivo, dentre outros, de se situar o período: outubro/79 à março/80.

O segundo tipo de abordagem, assunto tratado no presente artigo, considera as diversificaçōes das características morfométricas (notadamente altimetria e orientação do relevo) e alguns aspectos da cobertura vegetal da área. Para tanto, utilizou-se de um período amostral, primavera-verão 79/80 (outubro-março), definido como sendo significativo do comportamento climático usual, dessa época do ano, no Horto Florestal. O grau de significância do periodo em questão foi estabelecido em função de sua comparação com os demais períodos primavera-verão, abrangidos pela série climática (46-81) estudada no primeiro tipo de abordagem a que se refere o parágrafo anterior.

No decorrer do período amostral, acima mencionado, o comportamento climático passa a ser analisado em função de pontos amostrais, distribuídos dentro da área de estudo, e detalhado para uma caracterização em níveis diário e horário. Para isso, durante outubro/79 à março/80, realizaram-se observaçōes de $30 \mathrm{em} 30$ minutos, durante $11 \mathrm{~h}$. diurnas ( $7 \mathrm{~h} 30$ à $18 \mathrm{~h} 30$ ), em 12 pontos amostrais (Fig. 2). Tais observaçōes referem-se à temperatura do ar seco (ta), temperatura do ar úmido (tu), umidade relativa, analisadas quantitativamente e, direção do vento e nebulosidade, analisados qualitativamente. Nesta abordagem a área será climaticamente descrita através das variáveis termo-higrométricas do ar e do regime de ventos.

A escolha dos pontos amostrais foi feita de maneira semi-aleatória; alguns foram definidos em função de sítios para os quais se previam futuras alterações, outros em função da estimativa de características morfométricas diferenciadas, uma vez que não se dispunha de cartas precisas da compartimentação fisiográfica do Horto.

Devido à impossibilidade de se sistematizar as observações horárias, de forma que elas fossem simultâneas nos 12 pontos amostrais, optou-se pela simultaneidade das mesmas em pelo menos 3 pontos, mantendo-se sempre 1 ponto $\left(P_{0}\right)$ em comum a todas elas, no qual as observaçōes pudessem ser mantidas durante todo o período amostral (cut/79-mar/80). Os dias nos quais se realizaram as observaçōes foram agrupados de 


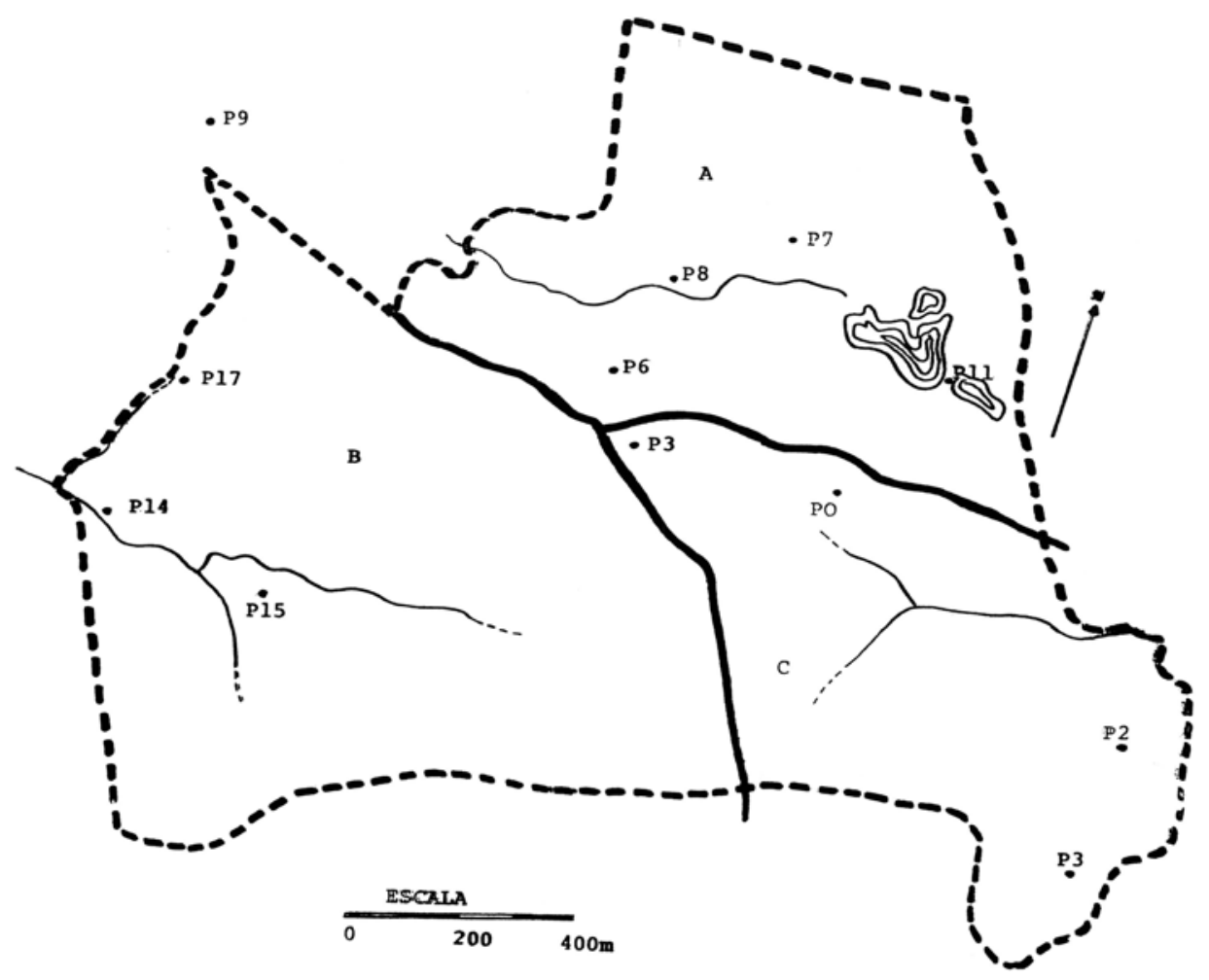

Fig. 2 - Pontos amostrais do clima, do Parque Estadual da Capital.

acordo com situaçōes de tipos de tempo bem definidas: pré-frontais, frontais e pós-frontais. Isto permite chegar-se à uma caracterização cliınática que leve em conta os tipos de tempo mais expressivos quanto a variação diurna dos elementos climáticos (Monteiro 1971).

Todavia, no decorrer de apenas 6 meses (abrangendo apenas 2 estaçōes de 1 dado ano, no caso primavera-verão de $79 / 80$ ) a frequência relativamente baixa de tais tipos de tempo não possibilita a obtenção de amostras consideradas grandes, em termos estatísticos. Assim, para se analisar os dados obtidos baseou-se na teoria estatística de pequenas amostras, utilizando-se a distribuição Studentt como aproximação da Normal Padrão (Gregory 1973). Foram analisados os parâmetros descritivos das amostras dos diferentes pontos de medição, o grau de correlação existente entre as mesmas e foram estabelecidas curvas de regresão para estimativas de temperatura em função dos valores registrados em $\mathrm{P}_{\mathrm{o}}$, quando isto se fizesse necessário. Os parâmetros estatísticos foram determinados considerando-se n-1 graus de liberdade e, os resultados obtidos através das análises efetuadas são estatistieamente válidos dentro de um limite de $95 \%$ de confiabilidade.

A escala adotada para representação da variação espacial do comportamento climático foi a de 1:2000 e os equipamentos para as mediçōes das variáveis climáticas foram colocados a $1,5 \mathrm{~m}$. do nivel do solo. Portanto, pode-se considerar este estudo como sendo de compartimentação microclimática (Sakiamurtti 1972) da área. 


\section{Resultados}

Por não se ter entrado no mérito do primeiro tipo de abordagem, referente aos aspectos climáticos, mencionado no item "Material e Método" e para ter-se uma idéia do peńodo amostral em face do comportamento climático usual do Horto, cabe aqui o seguinte esclarecimento:

Os anos 1979 e 1980, bem como os meses abrangidos pelo período amostral (outubro à março) dentro desses anos, comportaram-se climaticamente dentro dos limites evidenciados como usuais, no decorrer de 36 anos. A variabilidade média dos elementos climáticos durante o período amostral se manteve dentro do limite de 2 desvios padrões da série de 36 anos. Este fato permitiu considerar os resultados obtidos como sendo representativos do microclima da área durante a primavera-verão, no caso dos elementos climáticos considerados.

Através da análise dos dados referentes ao período amostral chegou-se aos seguintes resultados que são apresentados nas Tabelas 1-4.

TABELA 1: Caracteristicas termo-higrométricas e direção de vento por pontos amostrais (média diurna para dias com tipo de tempo PRÉ-FRONTAL - perfodo primavera-verăo). ta = temperatura do ar seco; tu = temperatura do ar úmido; UR = umidade relativa do ar.

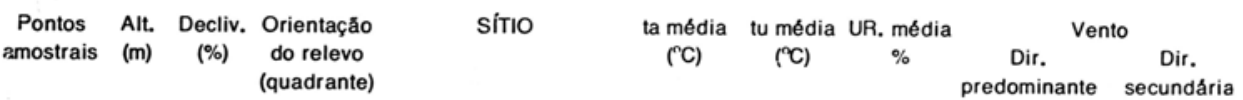

BACIA HIDROGRÁFICA A (SENTIDO: WSW $\rightarrow$ ENE); SETOR NNE DO HORTO

\begin{tabular}{|c|c|c|c|c|c|c|c|c|c|}
\hline P9 & 810 & $15-25$ & V.E. & urbanizado & 24,9 & 21,3 & 73,8 & $\mathrm{C}$ & NW \\
\hline P6 & 800 & $25-40$ & V.N. & $\begin{array}{l}\text { orla de mata } \\
\text { (eucalipto) }\end{array}$ & 28,0 & 21,3 & 56,7 & NW & - \\
\hline P8 & 780 & $25-40$ & V.S. & $\begin{array}{l}\text { espaço aberto } \\
\text { (capoeira baixa) }\end{array}$ & 27,3 & 21,2 & 59,0 & $\mathrm{~N}$ & - \\
\hline P7 & 778 & $0-5$ & vale & $\begin{array}{c}\text { espaço aberto } \\
\text { (entre asfalto e grama) }\end{array}$ & 26,5 & 19,9 & 59,1 & w & NW \\
\hline P11 & 775 & $0-5$ & vale & $\begin{array}{c}\text { espaço aberto } \\
\text { (entre lagos e solo } \\
\text { gramado) }\end{array}$ & 26,7 & 21,1 & 61,4 & w & $N$ \\
\hline
\end{tabular}

BACIA HIDROGRÁFICA B (SENTIDO: E $\rightarrow$ W); SETOR WSW DO HORTO

\begin{tabular}{|c|c|c|c|c|c|c|c|}
\hline P17 & 775 & $5-15$ & V.w & $\begin{array}{c}\text { espaço aberto } \\
\text { (campo degradado) }\end{array}$ & 26,3 & 21,9 & 70,0 \\
\hline P15 & 757 & $0-5$ & vale & $\begin{array}{c}\text { orla de mata (pinheiro e } \\
\text { latifoliada) }\end{array}$ & 25,8 & 20,9 & 65,0 \\
\hline P14 & 756 & $0-5$ & vale & $\begin{array}{c}\text { espaço aberto (campo } \\
\text { degradado } c / \text { constru- } \\
\text { çбes esparsas) }\end{array}$ & 26,7 & 20,9 & 59,1 \\
\hline
\end{tabular}

BACIA HIDROGRÁFICA C (SENTIDO WNW $\rightarrow$ ESE); SETOR SSE DO HORTO

\begin{tabular}{|c|c|c|c|c|c|c|c|}
\hline P3 & 798 & $5-15$ & V.S & $\begin{array}{c}\text { espaço fechado (orla de } \\
\text { mata c/ construçסes es- } \\
\text { parsas) }\end{array}$ & 25,5 & 19,9 & 62,0 \\
\hline PO & 790 & $0-5$ & vale & $\begin{array}{l}\text { espaço aberto } \\
\text { (solo gramado) }\end{array}$ & 25,9 & 20,2 & 57,4 \\
\hline P2 & 785 & $15-25$ & V.N. & $\begin{array}{l}\text { espaço fechado } \\
\text { (c/ construçס́es) }\end{array}$ & 26,1 & 20,5 & 61,0 \\
\hline
\end{tabular}

TOPO (DIVISOR DE ÁGUAS ENTRE AS 3 BACIAS) 
IABELA 2: Características termo-higrométricas e direçăo do vento por pontos amostrais (média diurna para dias com tipo de tempo FRONTAL - per(odo primavera-verăo).

$\begin{array}{ccccccccc}\text { Pontos } & \text { Alt. } & \text { Decliv. Orientaçăo } & \text { Sítio } & \text { ta média tu média UR. média } & \text { Vento } \\ \text { amostrais } & (\mathrm{m}) & \begin{array}{c}(\%) \\ \text { do relevo } \\ \text { (quadrante) }\end{array} & & (\mathrm{C}) & \left({ }^{\circ} \mathrm{C}\right) & \% & \text { Dir. } & \text { Dir. } \\ \text { predominante } & \text { secundária }\end{array}$

BACIA HIDROGRÁFICA A (SENTIDO: WSW $\rightarrow$ ENE); SETOR NNE DO HORTO

\begin{tabular}{|c|c|c|c|c|c|c|c|c|c|}
\hline P9 & 810 & $15-25$ & V.E. & urbanizado & 21,6 & 20,4 & 90,0 & $\mathrm{~s}$ & sw \\
\hline P6 & 800 & $25-40$ & V.N. & $\begin{array}{c}\text { orla de mata } \\
\text { (eucalipto) }\end{array}$ & 23,7 & 20,5 & 76,9 & $N$ & $\mathrm{C}$ \\
\hline P8 & 780 & $25-40$ & v.s. & $\begin{array}{l}\text { espaço aberto } \\
\text { (capoeira baixa) }\end{array}$ & 22,9 & 20,5 & 80,6 & w & $E$ \\
\hline P7 & 778 & $0-5$ & vale & $\begin{array}{c}\text { espaço aberto } \\
\text { (entre asfalto e grama) }\end{array}$ & 22,9 & 19,8 & 77,8 & $\mathrm{~N}$ & W \\
\hline P11 & 775 & $0-5$ & vale & $\begin{array}{c}\text { espaço aberto } \\
\text { (entre lagos e solo } \\
\text { gramado) }\end{array}$ & 22,5 & 20,1 & 80,8 & $\mathrm{~S}$ & SE \\
\hline
\end{tabular}

BACIA HIDROGRÁFICA B (SENTIDO: E $\rightarrow$ W); SETOR WSW DO HORTO

\begin{tabular}{|c|c|c|c|c|c|c|c|c|}
\hline P17 & 775 & $0-15$ & V.w & $\begin{array}{c}\text { espaço aberto } \\
\text { (campo degradado) }\end{array}$ & 22,6 & 20,9 & 86,8 & NW \\
\hline P15 & 757 & 0.5 & vale & $\begin{array}{c}\text { orla de mata (pinheiro e } \\
\text { latifoliada) }\end{array}$ & 21,9 & 20,1 & 86,0 & SW \\
\hline P14 & 756 & $0-5$ & vale & $\begin{array}{c}\text { espaço aberto (campo } \\
\text { degradado cl constru- } \\
\text { çōes esparsas) }\end{array}$ & 23,4 & 20,5 & 78,4 & NW \\
\hline
\end{tabular}

BACIA HIDROGRÁFICA C (SENTIDO W.NW $\rightarrow$ ESE); SETOR SSE DO HORTO

$\begin{array}{cccccccccc}\text { P3 } & 798 & 5-15 & \text { V.S } & \begin{array}{c}\text { espaço fechado (orla de } \\ \text { mata } d \text { construçóes es- } \\ \text { parsas) }\end{array} & 22,5 & 20,0 & 81,4 & \text { W } & \text { SW/S } \\ \text { P0 } & 790 & 0-15 & \text { vale } & \begin{array}{c}\text { espaço aberto } \\ \text { (solo gramado) }\end{array} & 22,8 & 20,2 & 79,0 & \text { W } & \text { - } \\ \text { P2 } & 785 & 15-25 & \text { V.N. } & \begin{array}{c}\text { espaço fechado } \\ \text { (d construçōes) }\end{array} & 23,2 & 20,5 & 79,4 & \text { N } & \text { E }\end{array}$

TOPO (DIVISOR DE ÁGUAS DAS TRÊS BACIAS)

\begin{tabular}{|c|c|c|c|c|c|c|}
\hline $\begin{array}{ll}\text { P5 } & 812\end{array}$ & $0-5$ & -- & $\begin{array}{c}\text { espaço aberto ( } d \text { cons- } \\
\text { truçōes esparsas junto à } \\
\text { via asfaltada) }\end{array}$ & 22,0 & 19,9 & 79,0 \\
\hline
\end{tabular}

Considerando os resultados apresentados nas Tabelas 1-4, associados com as características altimétricas e a orientação do rêlevo de cada uma das 3 bacias hidrográficas abrangidas pela área do Horto Florestal e, através do uso de curvas de regressão, obtevese uma matriz síntese das características microclimáticas representadas pelas variáveis termo-higrométricas que está apresentada na Tabela 5.

\section{Discussão}

1. O comportamento climático médio diurno (período primavera-verão) nas 3 bacias hidrográficas do Horto:

Bacia Hidrográfica A: disposta no sentido WSW $\rightarrow$ ENE; situada no setor NNE do Horto; altitudes variando entre 770 a $810 \mathrm{~m}$ (desnivel da ordem de $40 \mathrm{~m}$ ).

É a área que apresenta maior variação termo-higrométrica entre seus compartimentos: temperatura do ar variando em média de 22,1 a $24,5^{\circ} \mathrm{C}$; umidade relativa com uma amplitude da ordem de 13,9\% (69,5 a 80,4\%). Devido à configuração da Bacia e à orientação do vale, predominam ventos de $\mathrm{E}, \mathrm{NE}$ e N; com direções secundárias variando de W e SW. 
TABELA 3: Caracteristicas termo-higrométricas e direçăo do vento por pontos amostrais (média diurna para dias com tipo de tempo POS-FRONTAL - perlodo primavera-verăo).

\begin{tabular}{|c|c|c|c|c|c|c|c|c|}
\hline $\begin{array}{l}\text { Pontos } \\
\text { amostrais }\end{array}$ & $\begin{array}{l}\text { Alt. } \\
\text { (m) }\end{array}$ & $\begin{array}{l}\text { Decliv. } \\
\text { (\%) }\end{array}$ & $\begin{array}{l}\text { Orientaçăo } \\
\text { do relevo } \\
\text { (quadrante) }\end{array}$ & sltio & $\begin{array}{c}\text { ta média } \\
\left({ }^{\circ} \mathrm{C}\right)\end{array}$ & $\begin{array}{l}\text { tu média } \\
\left({ }^{\circ} \mathrm{C}\right)\end{array}$ & $\begin{array}{l}\text { UR. média } \\
\%\end{array}$ & $\begin{array}{l}\text { Vento } \\
\text { Dir. }\end{array}$ \\
\hline
\end{tabular}

BACIA HIDROGRÁFICA A (SENTIDO: WSW $\rightarrow$ ENE); SETOR NNE DO HORTO

\begin{tabular}{|c|c|c|c|c|c|c|c|c|c|}
\hline P9 & 810 & $15-25$ & V.E. & urbanizado & 19,8 & 18,5 & 89,3 & SE & - \\
\hline P6 & 800 & $25-40$ & V.N. & $\begin{array}{l}\text { orla de mata } \\
\text { (eucalipto) }\end{array}$ & 22,1 & 19,6 & 79,4 & $\mathbf{E}$ & - \\
\hline P8 & 780 & $25-40$ & v.s. & $\begin{array}{l}\text { espaço aberto } \\
\text { (capoeira baixa) }\end{array}$ & 21,4 & 19,5 & 89,4 & NE & - \\
\hline P7 & 778 & $0-5$ & vale & $\begin{array}{c}\text { espaço aberto } \\
\text { (entre asfalto e grama) }\end{array}$ & 21,4 & 19,4 & 82,2 & NE & - \\
\hline P11 & 775 & $0-5$ & vale & $\begin{array}{c}\text { espaço aberto } \\
\text { (entre lagos e solo } \\
\text { gramado) }\end{array}$ & 21,7 & 19,4 & 81,8 & $\mathbf{E}$ & - \\
\hline
\end{tabular}

BACIA HIDROGRÁFICA B (SENTIDO: E $\rightarrow W$ ); SETOR WSW DO HORTO

\begin{tabular}{|c|c|c|c|c|c|c|c|c|c|}
\hline P17 & 775 & $5-15$ & v.w & $\begin{array}{l}\text { espaço aberto (campo } \\
\text { degradado } d \text { constru- } \\
\text { çoes esparsas) }\end{array}$ & 2n.n & 19,8 & 91,6 & $\mathbf{E}$ & - \\
\hline P15 & 757 & $0-5$ & $v_{c}{ }^{\circ}$ & $\begin{array}{c}\text { orla de mata (pinheiro e } \\
\text { latifoliada) }\end{array}$ & 20,5 & 19,0 & 87,3 & SE & s \\
\hline P14 & 756 & $0-5$ & vale & $\begin{array}{c}\text { espaço aberto c/constru- } \\
\text { çסes esparsas) }\end{array}$ & 22,0 & 20,3 & 83,2 & NE & - \\
\hline
\end{tabular}

BACIA HIDROGRÁFICA C (SENTIDO WNW $\rightarrow$ ESE); SETOR SSE DO HORTO

\begin{tabular}{|c|c|c|c|c|c|c|c|c|c|}
\hline P3 & 198 & $5-15$ & V.S & $\begin{array}{c}\text { espaço fechado (orla de } \\
\text { mata } d \text { construçöes es- } \\
\text { parsas) }\end{array}$ & 21,2 & 19,2 & 83,3 & NE & S/SE \\
\hline PO & 790 & $0-5$ & vale & $\begin{array}{l}\text { espaço aberto } \\
\text { (solo gramado) }\end{array}$ & 21,6 & 19,1 & 80,4 & $\mathbf{E}$ & - \\
\hline P2 & 785 & $15-25$ & V.N. & $\begin{array}{l}\text { espaço fechado } \\
\text { (c/ construçסes) }\end{array}$ & 22,1 & 19,6 & 80,2 & $E$ & $\mathrm{~s}$ \\
\hline
\end{tabular}

TOPO (DIVISOR DE AGUAS DAS TRES BACIAS)

\begin{tabular}{|c|c|c|c|c|c|c|}
\hline P5 & 812 & $0-5$ &.-- & $\begin{array}{c}\text { espaço aberto ( } d \text { cons- } \\
\text { truçōes esparsas junto à } \\
\text { via asfaltada) }\end{array}$ & 21,5 & 19,0 \\
\hline
\end{tabular}

Bacia Hidrográfica B: disposta no sentido $\mathrm{E} \rightarrow W$; situada no setor WSW do Horto; attitudes variando entre 750 a $790 \mathrm{~m}$, desnivel altimétrico da ordem de $40 \mathrm{~m}$.

Em termos de amplitude de variação termo-higrométrica, esta Bacia se caracteriza por apresentar um comportamento intermediário entre os extremos representados pelas Bacias A e C (a ser descrita a seguir). A temperatura do ar em média de 22,7 a $23,9^{\circ} \mathrm{C}$ e a umidade relativa variando entre 72,1 a $78,6 \%$ (amplitude: $6,5 \%$ ); havendo um acentuado predomínio de ventos de NW.

Bacia Hidrográfica C: disposta no sentido WNW $\rightarrow$ ESE; situada no setor SSE; altitudes variando em torno de 770 a $800 \mathrm{~m}$ (desnivel: $30 \mathrm{~m}$ ).

Dentro do Horto, esta é a área que apresenta menor variação termo-higrométrica diurna, com a temperatura do ar entre 23,0 a $23,8^{\circ} \mathrm{C}$ em média, a umidade relativa entre 71,2 a $74,4 \%$ (amplitude: $3,2 \%$ ); os ventos predominantes săo do quadrante $N$ (variando entre NE e NW) e os ventos de E se caracterizam como direção secundária.

Divisor de águas das 3 Bacias: Altitude acima de $800 \mathrm{~m}$; apresenta temperaturas da ordem de $22,8^{\circ} \mathrm{C}$ e umidade relativa de $75,8 \%$; predominam ventos de $\mathrm{E}, \mathrm{NE}$, direção concordante com aquela que se verifica normalmente no Horto Florestal, devido ao tipo de circulaçăo atmosférica secundária que afeta a cidade de Săo Paulo, nessa época do ano. 
TABELA 4: Caracteristicas termo-higromb́tricas e direçăo do vento por pontos amostrais (média diurna perlodo primaveraverăo).

\begin{tabular}{|c|c|c|c|c|c|c|c|c|}
\hline & Alt. & Decliv. & Orientaçăo & sitio & ta média & tu mødia & UR. média & Vento \\
\hline amostrais & (m) & $(\%)$ & $\begin{array}{l}\text { do relevo } \\
\text { (quadrante) }\end{array}$ & & ('C) & ('C) & $\%$ & $\begin{array}{cc}\text { Dir. } & \text { Dir. } \\
\text { predominante } & \text { secundâria }\end{array}$ \\
\hline
\end{tabular}

BACIA HIDROGRAFICA A (SENTIDO: WSW $\rightarrow$ ENE); SETOR NNE DO HORTO

\begin{tabular}{|c|c|c|c|c|c|c|c|c|}
\hline P9 & 810 & $15-25$ & V.E. & urbanizado & 22,1 & 20,0 & 83,4 & C \\
\hline P6 & 800 & $25-40$ & V.N. & $\begin{array}{l}\text { orla de mata } \\
\text { (eucalipto) }\end{array}$ & 24,5 & 20,4 & 70,1 & $w$ \\
\hline P8 & 780 & $25-40$ & v.s. & $\begin{array}{l}\text { espaço aberto } \\
\text { (capoeira baixa) }\end{array}$ & 23,8 & 20,1 & 72,3 & NE \\
\hline P7 & 778 & $0-5$ & vale & $\begin{array}{c}\text { espaco aberto } \\
\text { (entre asfalto e grama) }\end{array}$ & 23,9 & 19,5 & 69,5 & NE \\
\hline P11 & 775 & $0-5$ & vale & $\begin{array}{c}\text { espaço aberto } \\
\text { (entre lagos e solo } \\
\text { gramado) }\end{array}$ & 23,5 & 19,8 & 73,4 & $\mathbf{E}$ \\
\hline
\end{tabular}

BACIA HIDROGRÁFICA B (SENTIDO: E $\rightarrow$ W); SETOR WSW DO HORTO

\begin{tabular}{|c|c|c|c|c|c|c|c|c|}
\hline P17 & 775 & $5-15$ & v.w & $\begin{array}{c}\text { espaco aberto } \\
\text { (campo degradado) }\end{array}$ & 23,5 & 20,7 & 78,6 & NW \\
\hline P15 & 757 & 0.5 & vale & $\begin{array}{c}\text { orla de mata (pinheiro e } \\
\text { latiloliada) }\end{array}$ & 22,7 & 19.7 & 76,8 & C \\
\hline P14 & 756 & $0-5$ & vale & $\begin{array}{l}\text { espaço aberto (campo } \\
\text { degradado } d \text { constru- } \\
\text { cobes esparsas) }\end{array}$ & 23,9 & 20,1 & 72,1 & NW \\
\hline
\end{tabular}

BACLA HIDROGRÁFICA C (SENTIDO WNW $\rightarrow$ ESE); SETOR SSE DO HORTO

\begin{tabular}{|c|c|c|c|c|c|c|c|c|}
\hline P3 & 798 & $5-15$ & V.S & $\begin{array}{l}\text { espaco techado (orla de } \\
\text { mata of construçoes es- } \\
\text { parsas) }\end{array}$ & 23,0 & 19,6 & 74.4 & NE \\
\hline PO & 790 & $0-5$ & vale & $\begin{array}{l}\text { espaco aberto } \\
\text { (solo gramado) }\end{array}$ & 23,4 & 19,6 & 71,2 & NW \\
\hline P2 & 785 & $15-25$ & V.N. & $\begin{array}{l}\text { espaco techado } \\
\text { (d construçbes) }\end{array}$ & 23,8 & 20,1 & 72,8 & $\mathbf{N}$ \\
\hline
\end{tabular}

TOPO ( DIVISOR DE AGUAS DAS TRES BACIAS)

$\begin{array}{cccccccccc}\text { P5 } & 812 & 0.5 & -.- & \begin{array}{c}\text { espaço aberto (d cons- } \\ \text { truçסes esparsas junto a } \\ \text { via asfaltada) }\end{array} & 22,8 & 19,6 & 75,8 & \text { NE } & \text { E }\end{array}$

2. O comportamento climático médio diumo (perlodo primavera-verão) considerando-se área total do Horto:

A variação altimétrica e a variaçăo térmica diurna evidenciam uma certa tendência correlativa direta, embora não se possa afirmar que essa correlação seja acentuada. Isto significa que, dentro da área do Horto podem ocorrer anomalias, tais como a ocorrência de temperaturas relativamente menores em pontos localizados tanto a cerca de $800 \mathrm{~m}$, quanto em vales a cerca de $750 \mathrm{~m}$, como é o caso dos pontos $\mathrm{P}_{8}$ e $\mathrm{P}_{15}$. Esse tipo de ocorrência pode ter sido provocado devido às condiçoës diferenciadas de sftio entre os dois pontos. $O$ primeiro, situado numa vertente $\mathrm{N}$, com uma declividade de 25 a $40 \%$, junto a um bosque de eucaliptos; o segundo, num vale voltado para $\mathrm{W}$, com uma declividade de $0-5 \%$, junto a um bosque de pinheiros e uma capoeira de mata latifoliada. Todavia, para se isolar o fator de maior peso quanto a interferência no comportamento termo-higrométrico em pontos isolados, dentro da área, seria necessário um período amostral muito maior e estudos mais detalhados, controlando-se cada uma das variáveis intervenientes. Neste estudo não seria possível, em face do tamanho das amostras e do tipo de dados disponíveis, afirmar categoricamente qual a causa dessa anomalia. 


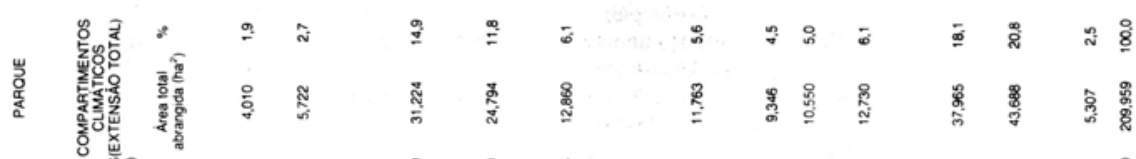

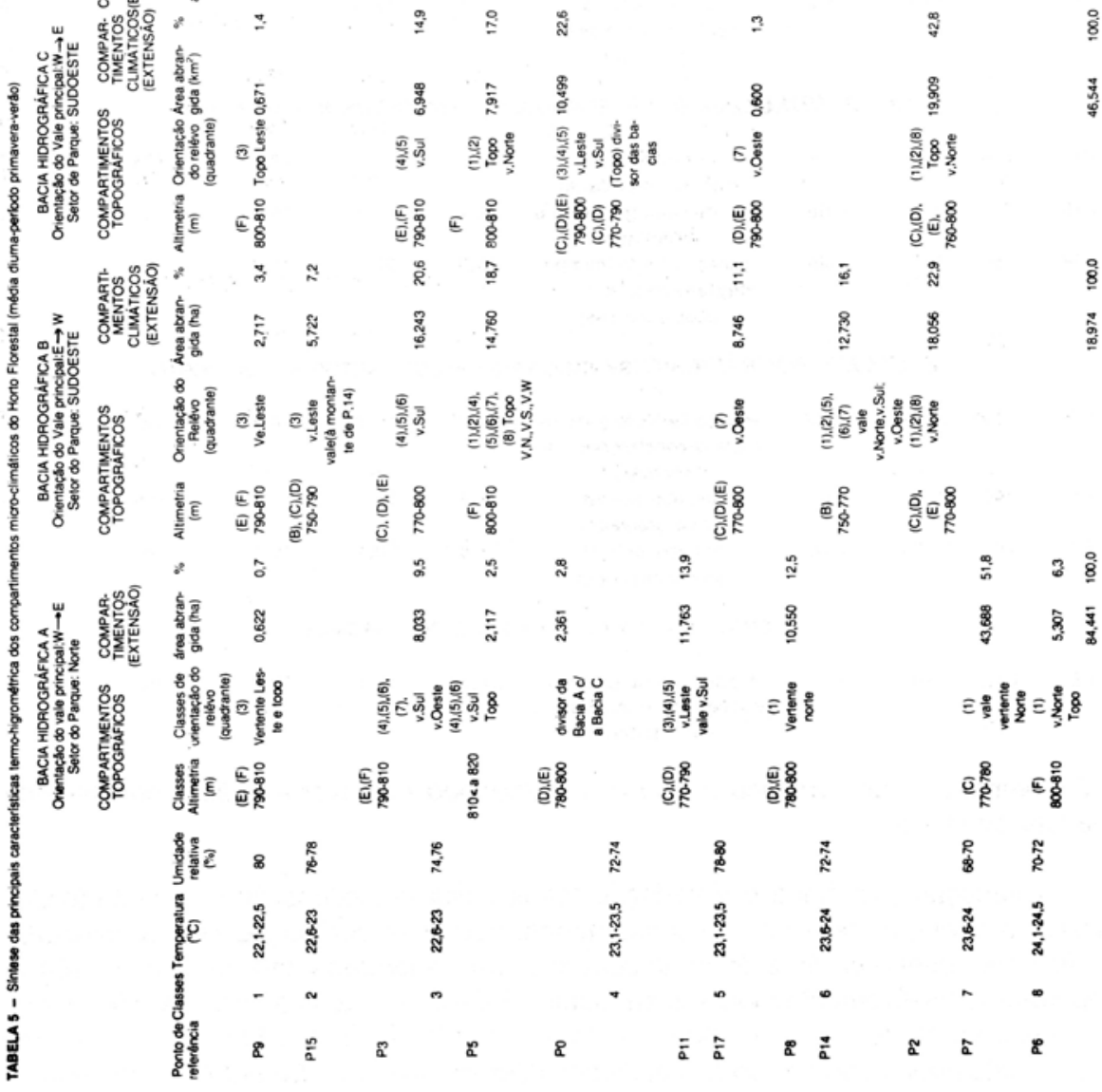


Sem considerar a altimetria e a cobertura vegetal, no que se refere às influências da orientação do relevo foi possivel notar que as vertentes voltadas para o norte tendem a ser mais aquecidas, apresentando teores mais baixos de umidade relativa do ar.

Quanto à variação da direção do vento, verificou-se que existe um predomínio de incidências de vento do quadrante $N$, prevalecendo ora ventos de $N E$, ora ventos de NW, dependendo do sentido em que se posicionam os vales. A título de hipótese, pode-se dizer que o fato do Horto Florestal limitar-se ao Norte com uma área cuja cobertura vegetal é muito mais densa (reserva da Cantareira) que a sua, com altitudes mais elevadas e com temperaturas mais baixas, propiciaria a formação de fluxos de ar direcionados para o Sul (área do Horto), gerados pela desigualdade de aquecimento térmico basal existente entre as duas áreas.

\section{Conclusões}

Com base nos resultados das análises de amostras pequenas, referentes ao perido primavera-verão e apesar dos tipos de dados disponiveis, foi possível constatar que:

As três bacias hidrográficas existentes dentro do Horto Florestal consistem em três macro-compartimentos muito bem individualizados quanto à variação temo-higrométrica e quanto ao regime de ventos.

Dessas três bacias, a que apresenta maior homogeneidade microclimática dentro de sua área é a Bacia C, situada no setor SSE da área do Horto, sendo a única que não se limita com a Reserva Florestal da Cantareira. Portanto, é muito provável que a maior proximidade das outras duas bacias hidrográficas com a reserva florestal seja um fato significativo, interferindo mais acentuadamente nos mecanismos microclimáticos das mesmas, sobretudo quanto ao regime de ventos.

Levando-se em conta a experiência adquirida na realização deste trabalho, pode-se afirmar que é extremamente difícil elaborar estudos desta natureza sem se dispor, antes da escolha dos pontos amostrais de observaçōes, de cartas geomorfológicas e de cobertura vegetal detalhadas o suficiente para permitir uma compartimentação precisa da área, em função de suas características fisiográficas. No que se refere ao período amostral para as observaçōes de detalhe, o ideal seria pelo menos 1 ano de observaçōes simultâneas nos pontos distribuídos dentro da área de estudo; isto possibilitaria uma análise mais precisa do comportamento microclimático no decorrer das quatro estações do ano.

\section{Referências Bibliográficas}

BRASIL. MINISTÉRIO DA AGRICULTURA. COMISSĀO DE SOLOS 1960. Carta dos solos do Estado de São Paulo. (Rio de Janeiro), 1:500000, 2 fl.

DE BIASI, M. 1973. Medidas gráficas de uma carta topográfica. São Paulo, Universidade de Sảo Paulo, Instituto de Geografia. 11p (35 Caderno de Ciência da Terra).

EITEN, G. 1970. A vegetação do Estado de São Paulo. São Paulo, Boletim do Instituto de Botânica 7: 7-8, jan. 1970.

EMPRESA METROPOLITANA DE PLANEJAMENTO DA GRANDE SĀO PAULO (EMPLASA) 1980. Carta geologica da regiāo metropolitana da Grande São Paulo, 1:100000, 2 fl.

GREGORY, S. 1973. Statistical methods and geographers. Longman Group Ltd., London.

MITCHELL, C. 1973. Terrain evaluation. Longman Group Ltd., London. 31-37.

MONTEIRO, C.A. de F. 1971. Análise rftmica em climatologia. São Paulo, Universidade de São Paulo, Instituto de Geografia. (1 Climatologia).

OLIVEIRA, M.C. 1984. Construção de uma carta para determinaçāo de orientação de vertentes. Rev. IG, Sāo Paulo 5: 47-50.

SAKIAMURTTI, R. 1972. Micrometeorology. Apostila de curso de pós-graduação (inédito), Instituto de Pesquisas Espaciais (INPE), Săo José dos Campos.

SCHINDLER, N. 1975. Leitlinien für das Berlinenstadtgrün. In Das Gartenamt 24: 431-436. 